\title{
Aplikasi BRT Trans Semarang Berbasis Android
}

\author{
Priskila Penny Ardiana ${ }^{1}$, Lalang Erawan ${ }^{2}$ \\ Program Studi Sistem Informasi, Fakultas Ilmu Komputer, Universitas Dian Nuswantoro \\ Jl. Imam Bonjol no. 27, Semarang, 50131, Telp. (024)3520165, Fax. (024)3569684 \\ ${ }^{1}$ priskapenny.ppa@gmail.com, ${ }^{2}$ lalang.erawan@dsn.dinus.ac.id
}

Diterima: 19 Juli 2019; Direvisi: 29 Nopember 2019; Disetujui: 30 Nopember 2019

\begin{abstract}
Abstrak
BRT Trans Semarang adalah sarana transportasi yang disediakan pemerintah Kota Semarang. Informasi tentang layanan BRT seperti rute, shelter, koridor, dan jadwal BRT perlu disampaikan kepada masyarakat. Pemerintah Kota Semarang sudah memasang informasi di beberapa tempat seperti di shelter dan kantor BRT Trans Semarang. Penyampaian informasi layanan akan lebih efektif lagi dengan memanfaatkan teknologi informasi khususnya teknologi mobile. Penelitian akan mengembangkan aplikasi layanan informasi BRT Trans Semarang dengan basis sistem operasi Android. Metode pengembangan sistem yag digunakan waterfall, bahasa yang digunakan meliputi HTML, CSS, Javascript, XML, PHP, Android Webview dan MySQL sebagai database penyimpanan datanya. Sedangkan proses pengujian aplikasi menggunakan metode blackbox dan UAT. Akhir dari penelitian ini, aplikasi yang direncanakan telah berhasil diwujudkan. Aplikasi dapat menghasilkaniInformasi lokasi shelter BRT dan pencarian rute pada 7 koridor. Selain itu, aplikasi dapat memberikan informasi lokasi shelter terdekat dari pengguna serta dapat membantu dalam pencarian rute. Pengujian UAT menunjukkan aplikasi dapat diterima berdasarkan kemudahan penggunaan serta informasi yang mudah dipahami.
\end{abstract}

Kata kunci: Waterfall, Android, Android Webview, BRT Trans Semarang

\begin{abstract}
BRT Trans Semarang is a transportation facility provided by the Semarang City government. Information about BRT services such as routes, shelters, corridors, and BRT schedules needs to be shared to public. The Semarang City Government has posted information in several places such as the Trans Semarang shelter and BRT office. Submission of information services will be even more effective by utilizing information technology, especially mobile technology. The research will develop the BRT Trans Semarang information service application based on the Android operating system. The system development method used is waterfall, the language used includes HTML, CSS, Javascript, XML, PHP, Android Webview and MySQL as the data storage. While the application testing process uses the blackbox and UAT methods. At the end of this study, the planned application has been successfully realized. The application can generate BRT shelter location information and route search in 7 corridors. In addition, the application can provide information on the location of the nearest shelter from the user and can help in the search for routes. UAT testing shows applications can be accepted based on ease of use as well as information that is easily understood.
\end{abstract}

Keywords: Waterfall, Android, Android Webview, BRT Trans Semarang

\section{PENDAhULUAN}

BRT Trans Semarang sebagai program angkutan umum massal yang lebih aman, cepat, 
murah dan bersifat massal telah diterapkan Pemerintah Kota Semarang sejak tahun 2009 dengan nama BRT Trans Semarang. Semula pengelolaan dilakukan oleh Pemerintah Kota Semarang bekerjasama dengan PT Trans Semarang. Kemudian sejak tahun 2017, pengelolaan dilakukan oleh BLU (Badan Layanan Umum) UPTD (Unit Pelaksana Teknis Daerah) Trans Semarang. Dalam operasionalnya, BRT Trans Semarang membagi area layanannya menjadi 7 koridor. Koridor tersebut meliputi koridor 1 Mangkang-Penggaron, koridor 2 Terboyo-Sisemut Ungaran, koridor 3 Pelabuhan Tanjung Mas-Taman Diponegoro, koridor 4 Cangkiran-Bandara A Yani, Koridor 5 Meteseh-PRPP, koridor 6 UNDIP-UNNES, dan koridor 7 Genuk-Balaikota.[1]

Informasi kegiatan operasional BRT Trans Semarang diperlukan oleh pengguna agar mereka dapat mudah memilih dan menentukan bus BRT yang harus digunakan agar sesuai dengan tujuan mereka. Informasi ini telah dipasang BLU UPTD Trans Semarang di beberapa tempat seperti di shelter dan shelter transit serta beberapa tempat strategis lain. Agar sesuai dengan tuntutan jaman serta lebih memudahkan pengguna BRT Trans Semarang untuk menggunakan alat transportasi ini, informasi yang diberikan dapat diperluas jangkauannya dengan memanfaatkan teknologi mobile. Dengan aplikasi mobile yang dijalankan pada perangkat ponsel pintar, informasi dapat diakses oleh pengguna setiap saat dan dimana saja.

Penelitian sebelumnya tentang pengembangan aplikasi layanan informasi BRT Trans Semarang, terdapat penggunaan jenis layanan Location-based Service (LBS) dan teknologi Global Positioning System (GPS) untuk memberikan informasi berbasis lokasi [2][3][4]. LBS merupakan layanan informasi dan atau entertainment yang diberikan melalui media ponsel pintar dengan menggunakan lokasi geografi dari perangkat yang digunakan[5]. LBS menggunakan teknologi GPS untuk memperoleh informasi lokasi dan waktu yang diperlukan untuk menghadirkan informasi berbasis lokasi[6]. Informasi layanan BRT disajikan menggunakan perangkat ponsel pintar yang memiliki fitur tracking GPS. Untuk menyajikan informasi layanan BRT melalui perangkat ponsel pintar ini, peneliti menggunakan aplikasi Google map[2][4].

Hasil aplikasi dari penelitian sebelumnya memberikan informasi layanan BRT meliputi jalur rute BRT[2][3][4], jadwal keberangkatan BRT[2][3], dan lokasi shelter[4]. Pada penelitian [4], aplikasi juga dapat menampilkan informasi tentang lokasi shelter terdekat dengan pengguna sekaligus menunjukkan arah dari lokasi pengguna ke shelter terdekat. Algoritma Dijkstra digunakan untuk menghitung dan menentukan jalur rute BRT[2][3]. Database yang digunakan dalam penelitian antara lain PostgreSQL[4] dan MySQL[2].

Dalam hal pengujian, penelitian sebelumnya[2] menggunakan metode white box untuk memastikan semua perintah dan kondisi pada fitur utama dieksekusi secara minimal. Pengujian menggunakan flow graph untuk menggambarkan alur algoritma dan graph matrix untuk menggenerasi flow graph. Metode komunikasi check in digunakan untuk mengetahui hasil pertukaran data dalam web service. Metode pengujian perangkat keras bertujuan untuk menguji kompatibilitas aplikasi pada berbagai perangkat ponsel pintar[2]. Penelitian [4] menguji kinerja aplikasi di berbagai lokasi yang berbeda. Aplikasi diuji di berbagai lokasi untuk menguji kemampuannya dalam menampilkan informasi shelter terdekat.

Sebagai sebuah sistem, aplikasi android yang dibangun dalam penelitian memerlukan metode pengembangan sistem untuk memandu proses pengembangan. Penelitian [2] dan [3] menggunakan metode pengembangan sistem waterfall. Metode ini dipilih karena metode waterfall relatif lebih mudah dimengerti dan digunakan dan persyaratan sistem bersifat stabil[7].

Kajian terhadap penelitian sebelumnya menunjukkan bahwa informasi yang dibuat berupa informasi lokasi shelter, rute, dan jadwal keberangkatan. Aspek lokasi dari informasi direalisasikan dengan memanfaatkan layanan Local-based Services dan teknologi GPS. Algoritma Dijkstra digunakan untuk menghitung dan menentukan rute, metode pengembangan sistem yang digunakan waterfall, dan informasi disajikan dalam bentuk grafis dengan memanfaatkan aplikasi Google Map.

Penelitian ini akan mengembangkan aplikasi mobile dengan sistem operasi Android untuk memberikan layanan informasi kegiatan operasional BRT Trans Semarang. Jenis layanan informasi yang diberikan berupa informasi lokasi shelter yang dapat mendeteksi shelter terdekat dari lokasi pengguna aplikasi dan informasi jalur rute BRT yang akan dilalui oleh pengguna 
aplikasi. Layanan Local-based Services dengan teknologi GSP digunakan untuk memperoleh konteks lokasi dari informasi. Sementara untuk penghitungan dan penentuan rute menggunakan algoritma dijkstra. Perancangan sistem menggunakan metode waterfall dan source code aplikasi dibuat dengan menggunakan bahasa PHP, javascript, XML, serta database MySQL.

\section{METODE PENELITIAN}

Data penelitian mencakup data jalur rute, pembagian koridor, dan lokasi shelter. Pengumpulan data dilakukan dengan mempelajari dokumentasi program BRT dari pengelola BLU BRT Trans Semarang, serta mempelajari pustaka dari sumber lain seperti internet.

Tahap pengembangan aplikasi menggunakan metode waterfall dimulai dari pengumpulan persyaratan atau kebutuhan sistem sampai dengan pengujian sistem. Proses pengembangan selengkapnya sebagai berikut:

1. Requirements Definition

Kebutuhan atau persyaratan aplikasi diidentifikasi pada tahap ini. Persyaratan yang diidentifikasi meliputi persyaratan fungsional aplikasi yang akan menjadi fitur-fitur aplikasi, persyaratan perangkat lunak seperti perangkat lunak bantu konversi Webview yang dibutuhkan untuk mengkonversi aplikasi dari basis web menjadi berbasis android. Data-data BRT yang dikumpulkan meliputi jalur rute BRT, pembagian koridor, dan lokasi shelter termasuk shelter transit.

2. System and Software Design

Setelah kebutuhan aplikasi diketahui, langkah berikutnya membuat rancangan aplikasi mencakup fitur, database, antarmuka aplikasi. Kegiatan tahap ini dibagi menjadi dua kelompok kegiatan, yaitu:

a. Pemodelan UML

Diagram-diagram UML digunakan dalam suatu perancangan sistem untuk memodelkan aspek-aspek sistem. Aspek-aspek perilaku sistem atau aplikasi dimodelkan menggunakan diagram use case, sekuensial, dan aktivitas. Pemodelan ini menjelaskan fungsional aplikasi, aliran pesan, dan kolaborasi diantara obyek-obyek aplikasi. Kemudian entitasentitas aplikasi dimodelkan menggunakan diagram kelas. Diagram ini nanti akan menjadi sumber rancangan struktur database yang digunakan aplikasi.

b. Desain antarmuka

Antarmuka yang akan dirancang terdiri dari antarmuka input dan output aplikasi. Aplikasi akan menerima data eksternal maka memerlukan antarmuka input bagi pengguna untuk memasukkan data tersebut. Antarmuka ini perlu dirancang dengan baik sehingga mudah digunakan dan mendukung kinerja pengguna. Sedangkan rancangan output aplikasi menggambarkan jenis dan bentuk dokumen laporan yang dihasilkan oleh aplikasi baik media layar maupun printer.

3. Implementation and Unit Testing

Tahapan ini merupakan kegiatan untuk mengimplementasikan desain aplikasi menjadi bagian-bagian aplikasi berupa modul-modul program dan database. Bahasa pemrograman yang digunakan adalah bahasa pemrograman web yaitu HTML, CSS, XML, Javascript dan PHP. Data yang digunakan dalam aplikasi akan disimpan menggunakan DBMS MySQL.

4. Integration and System Testing

Pada tahap ini dilakukan pengujian terhadap aplikasi yang dikembangkan. Pengujian dilakukan terhadap sistem secara keseluruhan. Pengujian menggunakan metode Blackbox dan User Acceptance Test (UAT). Pengujian Blackbox untuk memastikan setiap output dari aplikasi telah sesuai dengan rancangan. Sedangkan pengujian UAT untuk memastikan aplikasi dapat diterima oleh calon pengguna. Pengujian UAT dilakukan dengan menyebar kuisioner kepada 30 responden yang diambil dari para pengguna BRT Trans Semarang. 


\section{HASIL DAN PEMBAHASAN}

\subsection{Identifikasi Masalah}

Program BRT yang dijalankan oleh Pemerintah Kota Semarang disambut positip masyarakat kota Semarang. Masyarakat kota semarang banyak yang menggunakan sarana transportasi umum ini untuk melakukan aktivitas sehari-hari mereka. Dari tahun ke tahun terjadi peningkatan jumlah pengguna BRT. Koridor BRT juga mengalami penambahan jumlah yang membuktikan bahwa pengguna BRT semakin lama menjadi semakin banyak. Saat penelitian ini dilakukan sudah terdapat 7 koridor yang beroperasi, yaitu koridor 1 Mangkang-Penggaron, koridor 2 Terboyo-Sisemut Ungaran, koridor 3 Pelabuhan Tanjung Mas-Taman Diponegoro, koridor 4 Cangkiran-Bandara A Yani, Koridor 5 Meteseh-PRPP, koridor 6 UNDIP-UNNES, dan koridor 7 Genuk-Balaikota[1].

Usaha yang dilakukan pemerintah untuk mempromosikan program BRT ini meliputi pemasangan iklan di shelter, tubuh bus, televisi, dan menjadi sponsor berbagai event yang diadakan oleh berbagai pihak. Selain itu pihak pengelola BRT juga menjalankan program touring BRT keliling kota Semarang yang bekerja sama dengan Dinas Pendidikan Kota Semarang.

Setelah masyarakat kota Semarang mengetahui keberadaan program BRT ini, maka tugas berikutnya yang harus dilakukan oleh pengelola BRT adalah memberikan pelayanan dengan baik. Salah satu bentuk layanan yang dilakukan adalah memberikan informasi yang cukup tentang berbagai hal yang perlu diketahui oleh pengguna BRT sehingga pengguna dapat menikmati layanan BRT dengan mudah dan senang. Salah satu informasi yang sangat dibutuhkan oleh pengguna adalah tentang kegiatan operasional BRT mencakup rute, koridor, lokasi shelter, shelter transit, dan jadwal keberangkatan BRT. Informasi ini disampaikan kepada pengguna dengan cara dipasang di shelter dan beberapa tempat lainnya seperti kantor BRT Trans Semarang.

Semakin banyak masyarakat yang mengetahui informasi operasional BRT, semakin banyak pengguna BRT. Dengan semakin banyak pengguna BRT, maka program BRT semakin berhasil. Di sisi lain, informasi yang dipasang di shelter hanya akan diketahui oleh masyarakat kalau mereka berada di shelter tersebut. Agar informasi tersebut mudah diperoleh dimana saja dan kapan saja maka perlu cara yang lebih efektif untuk menyebarkan informasi tersebut. Teknologi informasi berbasis mobile dengan kelebihannya dapat merealisasikan hal tersebut. Saat ini penggunaan perangkat ponsel pintar oleh masyarakat untuk memperoleh informasi sudah menjadi hal yang umum dan wajar. Maka jika penyebaran informasi layanan BRT melalui media jaringan mobile, hal ini akan membuat informasi tersebut akan mudah diperoleh dan dikonsumsi oleh masyarakat.

Aplikasi mobile yang akan dibangun menggunakan sistem operasi android.Aplikasi akan memberikan layanan informasi rute, koridor, dan lokasi shelter kepada pengguna. Bahasa yang digunakan untuk mengembangkan aplikasi adalah HTML, CSS, XML, CSS, Javascript, serta PHP yang merupakan bahasa web. Untuk mengkonversi aplikasi menjadi berbasis mobile akan digunakan salah satu tools android yaitu Webview.

\subsection{Identifikasi Kebutuhan Sistem}

Berdasarkan hasil identifikasi kebutuhan fungsional, aplikasi BRT yang akan dikembangkan akan memiliki fitur-fitur sebagai berikut:

1. Peta lokasi shelter yang akan menampilkan sebaran shelter pada 7 koridor BRT Trans Semarang. Fitur ini juga akan menampilkan lokasi pengguna, serta menyediakan menu filter untuk menampilkan shelter bedasarkan koridornya.

2. Fitur untuk menampilkan shelter terdekat dari lokasi pengguna.

3. Pencarian rute yang akan menampilkan rute yang dilewati berdasarkan shelter berangkat dan shelter tujuan yang dipilih oleh pengguna. Fitur ini juga menampilkan informasi nomor koridor shelter serta lokasi shelter transit.

Dalam proses pengembangan aplikasi BRT Trans Semarang berbasis android terdapat beberapa data dan informasi yang dibutuhkan agar aplikasi dapat memenuhi kebutuhan pengguna. Data dan informasi tersebut adalah: 
1. Data lokasi shelter di 7 koridor

2. Data rute yang dilewati 7 koridor

3. Informasi lokasi shelter

4. Informasi lokasi shelter terdekat

5. Informasi rute

Aplikasi akan berbasis Android maka diperlukan ponsel pintar untuk menjalankan aplikasi. Spesifikasi perangkat sebagai berikut:

1. Perangkat dengan sistem operasi android jellybean atau lebih

2. Perangkat android dengan fitur GPS

3. Perangkat android dengan koneksi jaringan internet

\subsection{Perancangan Aplikasi}

Perancangan aplikasi menggunakan alat pemodelan UML untuk menggambarkan setiap aspek dari aplikasi menggunakan setiap diagram UML yang bersesuaian.

\section{Use Case Diagram}

Use Case diagram digunakan untuk menggambarkan interaksi antara pengguna (aktor) dengan aplikasi yang dikembangkan dan menggambarkan fungsi-fungsi apa saja yang dapat diakses oleh aktor yang digambarkan melalui garis association. [8]

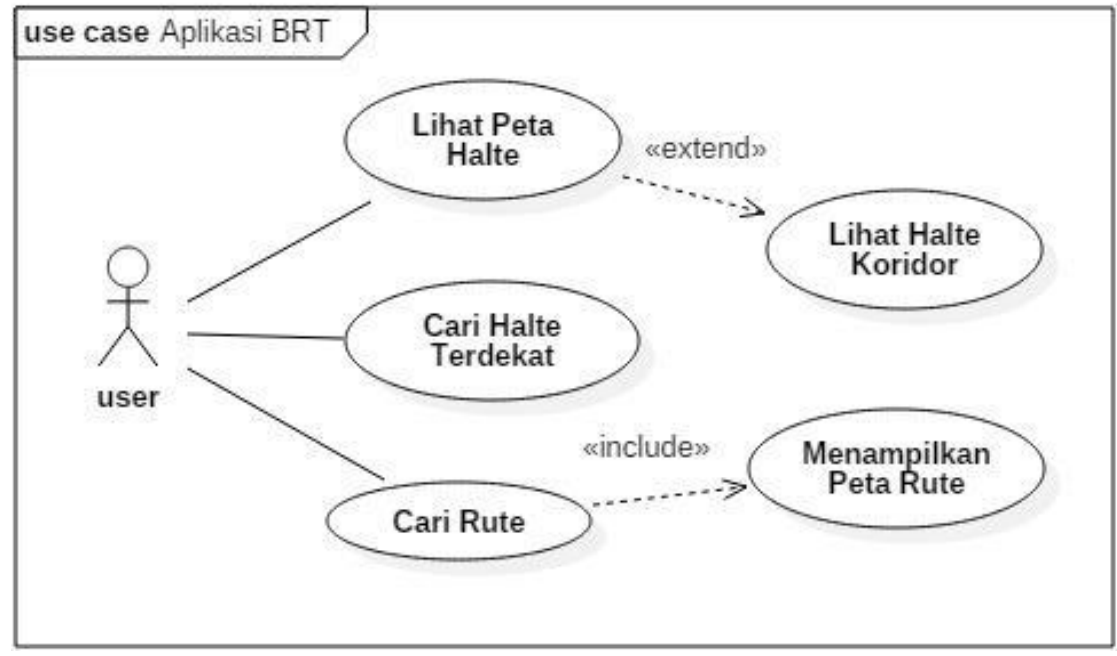

Gambar 1. Diagram Use Case Aplikasi BRT yang dikembangkan

Dalam gambar 1 diatas terdapat 5 use case dan pada use case 'Lihat Peta Halte' (halte sama dengan shelter) diperluas dengan use case 'Lihat Halte Koridor'. Struktur ini menjelaskan bahwa pengguna dapat meminta informasi shelter koridor pada saat melihat peta halte. Pada use case 'Cari Rute' menyertakan 'Menampilkan Peta Rute' yang menjelaskan bahwa pada saat pengguna mencari rute akan dibantu dengan informasi peta rute.

\section{Activity Diagram}

Activity diagram menggambarkan alur aktivitas pada sistem. Alur aksi reaksi pada skenario use case dijelaskan pada diagram ini. Aktivitas tersebut digambarkan oleh action state dengan transisi yang berarah.[9] Berikut ini diagram aktivitas tersebut. 
a. Activity Diagram Lihat Peta Halte

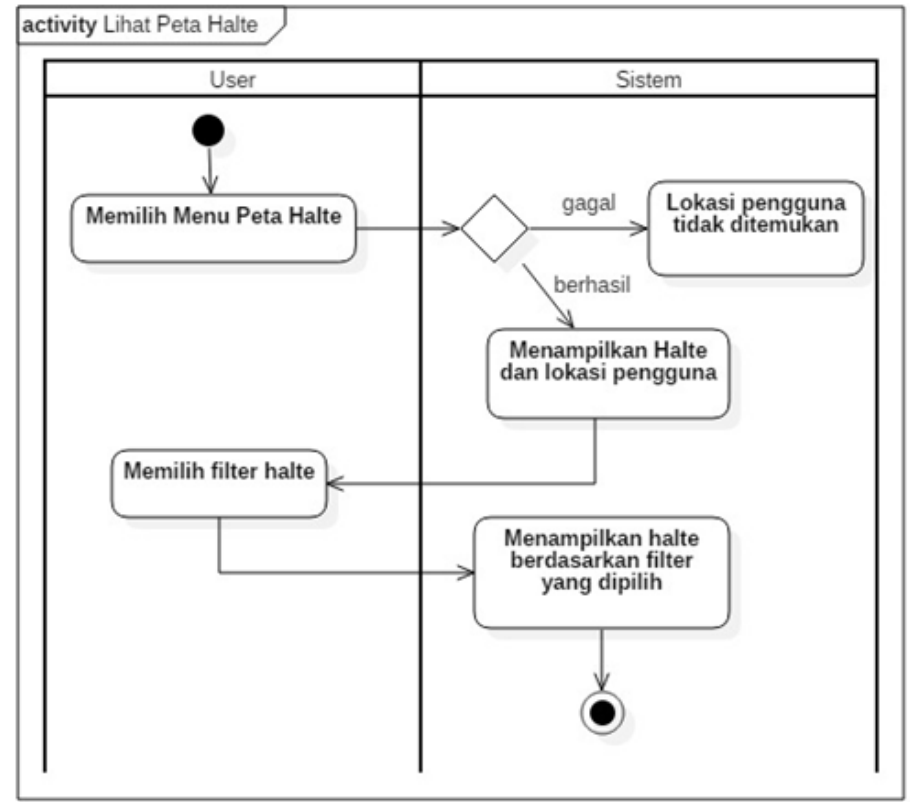

Gambar 2. Activity Diagram Lihat Peta Halte

Pada gambar 2 menunjukkan aktivitas melihat informasi shelter BRT melalui peta dimulai dengan memilih menu 'Peta Halte'. Aktivitas ini memiliki kemungkinan lokasi pengguna tidak ditemukan. Jika sebaliknya, maka informasi shelter dan lokasi pengguna ditampilkan. Informasi dapat disaring untuk memperoleh informasi yang diinginkan saja.

b. Activity Diagram Cari Halte Terdekat

Aktivitas pencarian shelter terdekat memiliki alur yang hampir sama dengan aktivitas melihat informasi peta halte yang ada pada gambar 3. Setelah informasi shelter terdekat lokasi pengguna ditampilkan, pengguna dapat memilih radius agar hanya shelter yang berada pada radius yang ditentukan saja yang ditampilkan.

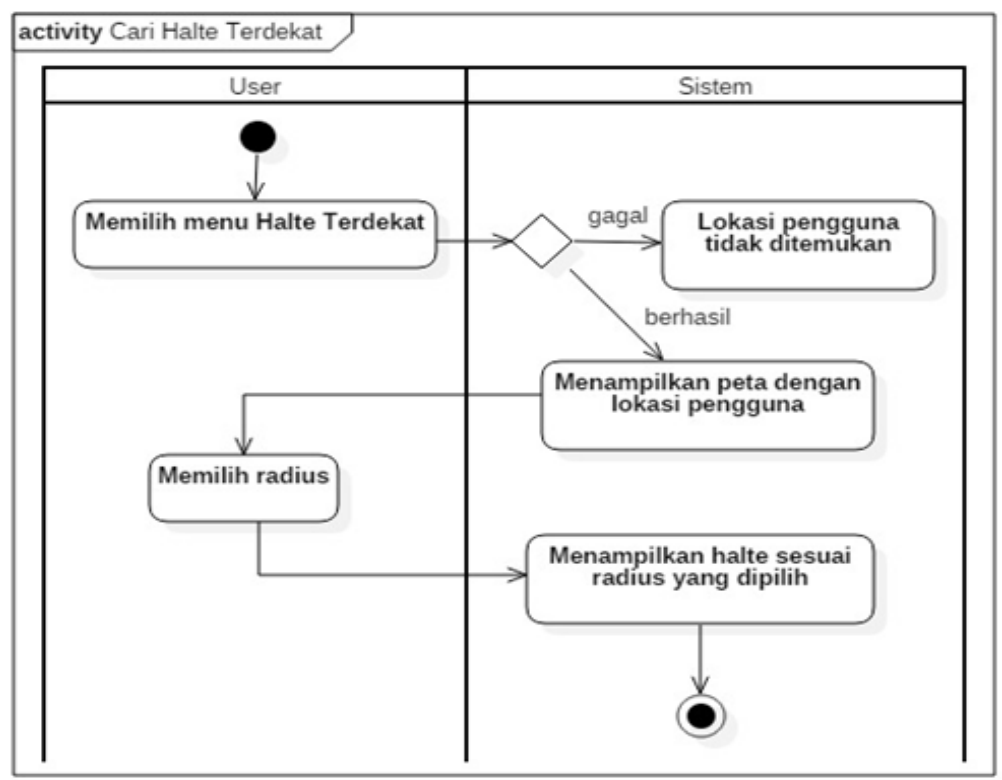

Gambar 3. Activity Diagram Halte Terdekat 
c. Activity Diagram Cari Rute

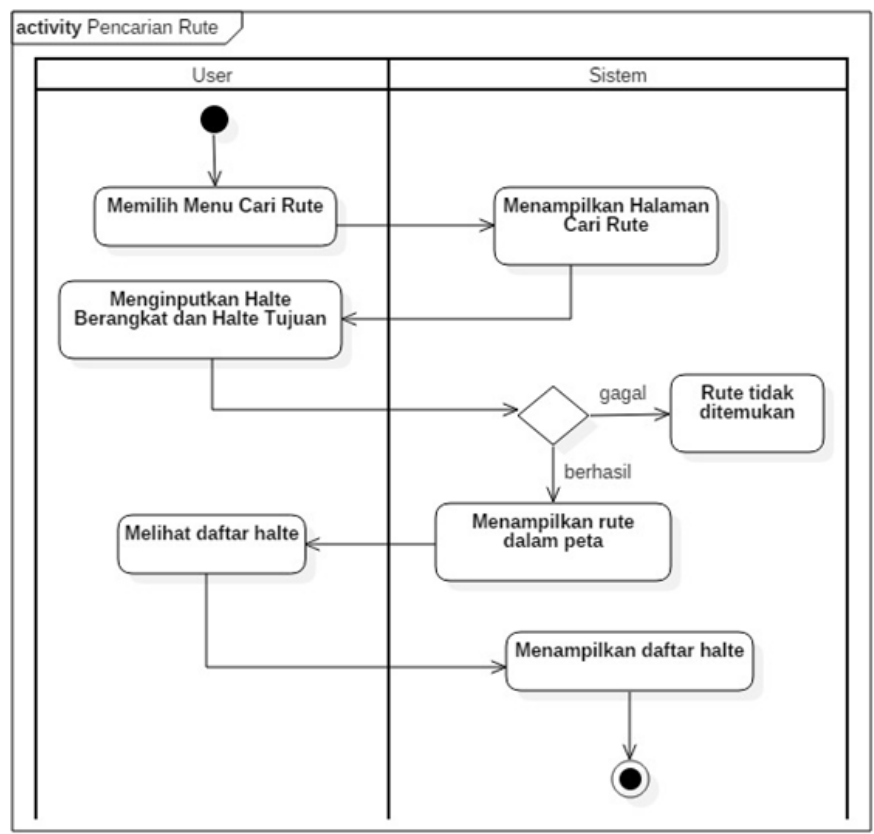

Gambar 4. Activity Diagram Cari Rute

Pada gambar 4 aktivitas pencarian informasi rute memerlukan masukan shelter berangkat dan tujuan. Jika ditemukan maka rute ditampilkan. Kemudian pengguna dapat memilih pilihan untuk melihat informasi daftar shelter bus BRT yang berada di rute tersebut.

\section{Sequence Diagram}

Sequence diagram menggambarkan aktivitas sistem berdasarkan waktu. Gambar 5,6,7 merupakan diagram yang menunjukkan aliran pesan yang mengalir diantara obyek-obyek sistem yang berkolaborasi pada suatu aktivitas [8].

a. Sequence Diagram Lihat Peta Halte

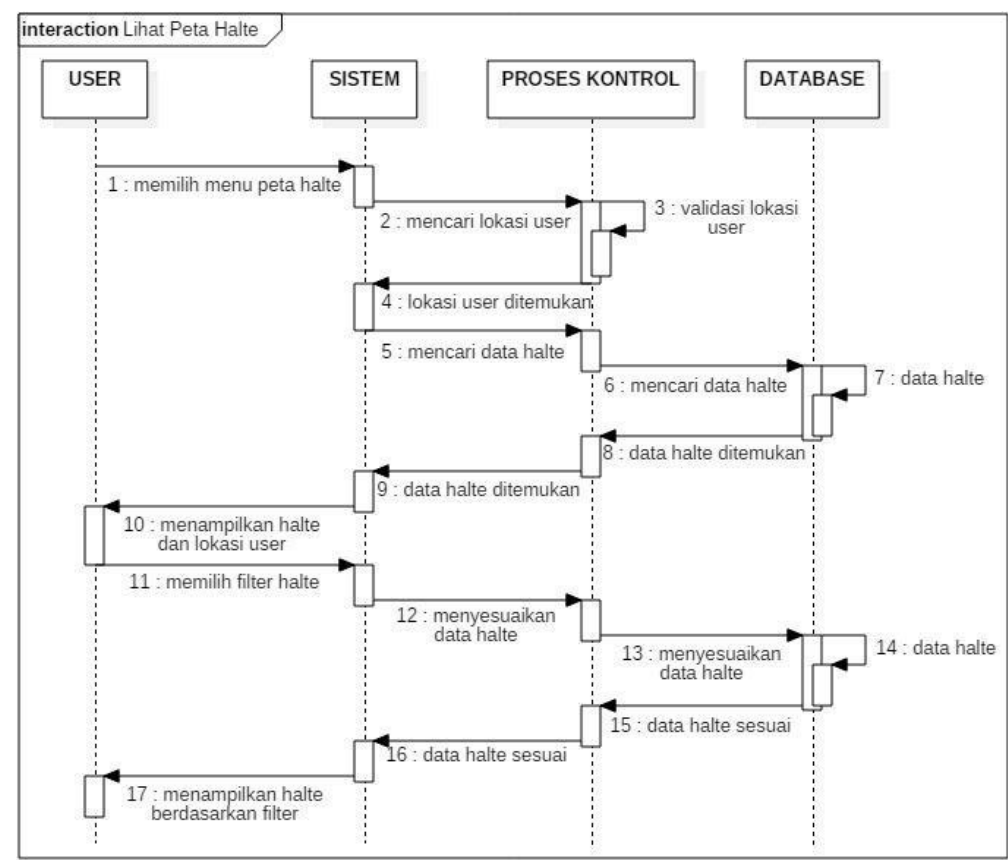

Gambar 5. Sequence Diagram Lihat Peta Halte 
b. Sequence Diagram Cari Halte Terdekat

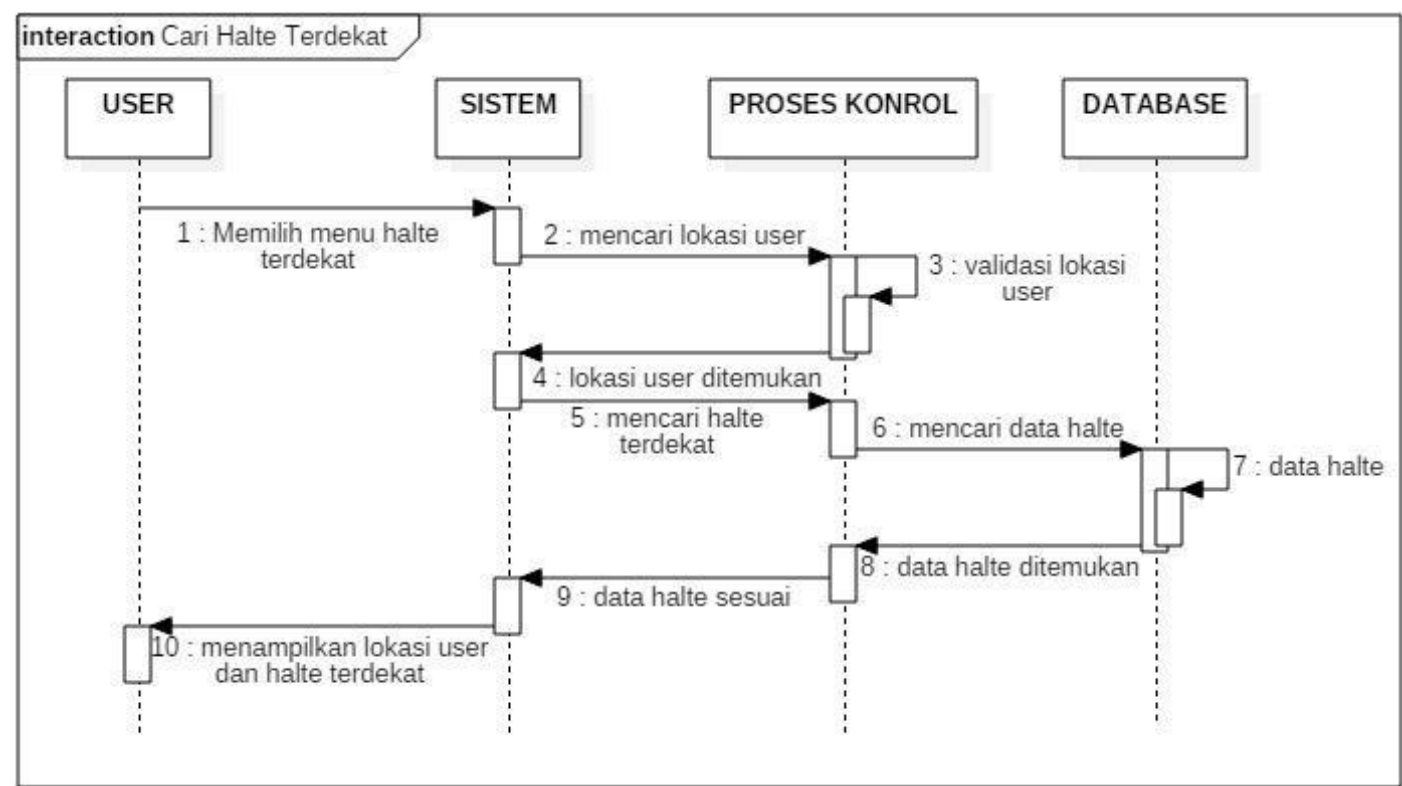

Gambar 6. Sequence Diagram Cari Halte Terdekat

c. Sequence Diagram Cari Rute

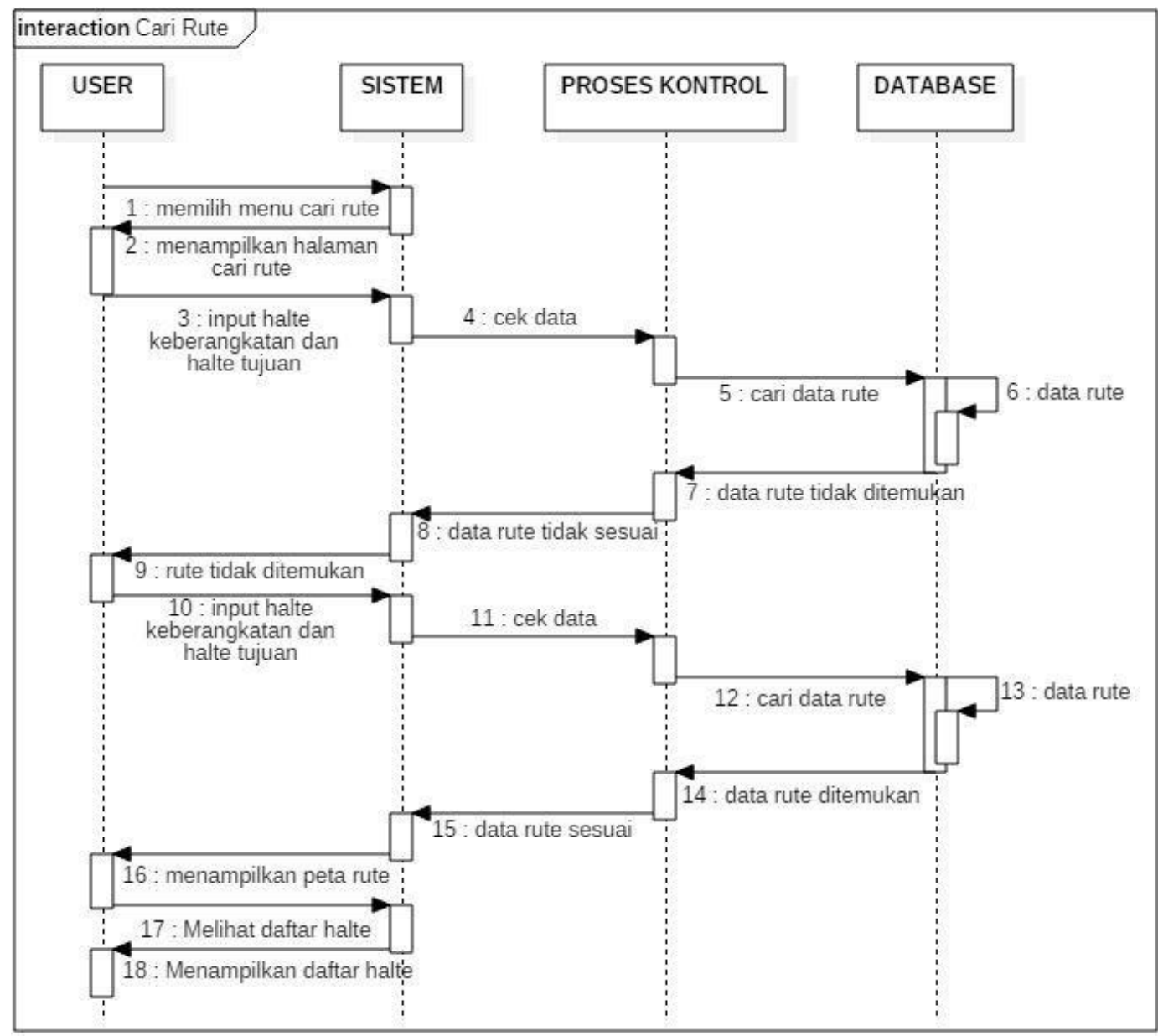

Gambar 7. Sequence Diagram Cari Rute 


\section{Class Diagram}

Class diagram menggambarkan entitas-entitas atau kelas-kelas sistem serta hubungannya. Setiap kelas memberikan informasi properti dan metodenya. [5] Berikut pada gambar 8 diagram kelas dari rancangan sistem.

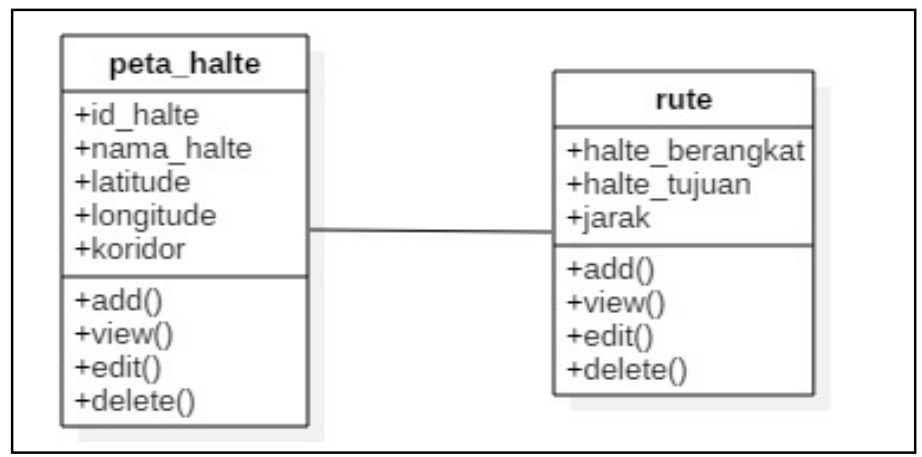

Gambar 8. Class Diagram Sistem

3.4 Implementation dan Pengujian Unit

Langkah selanjutnya setelah rancangan aplikasi selesai dibuat adalah menerapkannya menggunakan bahasa pemrograman yang sudah ditentukan.

\section{Halaman Utama}

Halaman utama diimplementasikan menggunakan framework bootstrap dengan bahasa pemrograman HTML dan CSS. Aplikasi yang dikembangkan memiliki halaman utama dengan menu peta halte, halte terdekat dan cari rute. Berikut pada gambar 9 tampilan halaman utama.

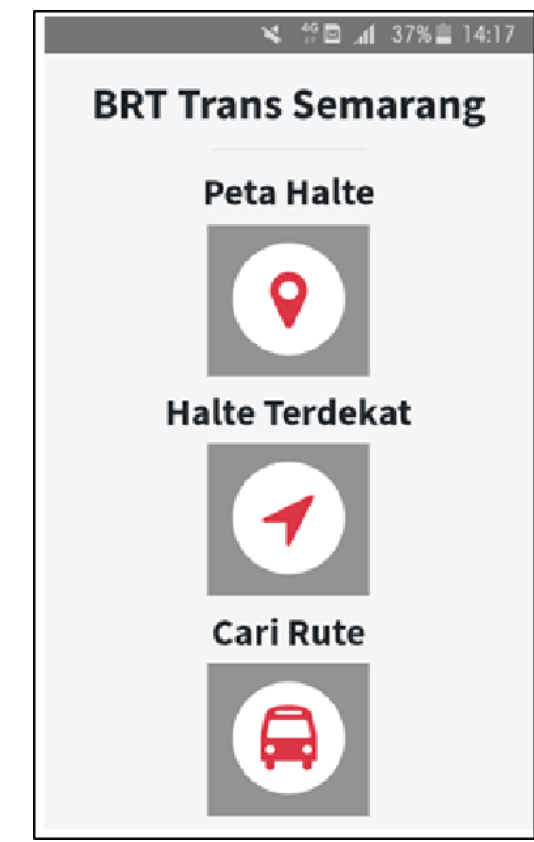

Gambar 9. Antarmuka Halaman Utama

2. Halaman Peta Halte

Halaman peta halte diimplementasikan menggunakan bahasa pemrograman PHP dan Javascript serta didukung XML dan Google Maps API. Halaman ini menampilkan peta dengan informasi sebaran lokasi shelter di 7 koridor BRT Trans Semarang. Selain itu, halaman peta 
halte juga akan menampilkan lokasi pengguna dan juga memberikan fitur filter halte seperti pada gambar 10 .

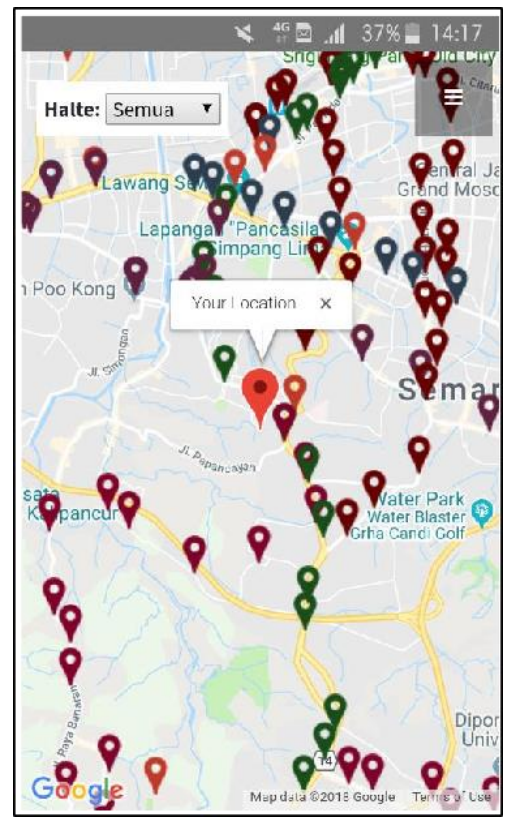

Gambar 10. Antarmuka Halaman Peta Halte

3. Halaman Halte Terdekat

Halaman pencarian halte terdekat digunakan untuk mencari shelter terdekat dari lokasi pengguna. Pencarian shelter terdekat didasarkan pada lokasi pengguna dan radius yang dipilih. Pilihan radius yang disediakan yaitu $300 \mathrm{~m}, 500 \mathrm{~m}, 700 \mathrm{~m}$ dan $1 \mathrm{~km}$ yang ditampilkan gambar 11.

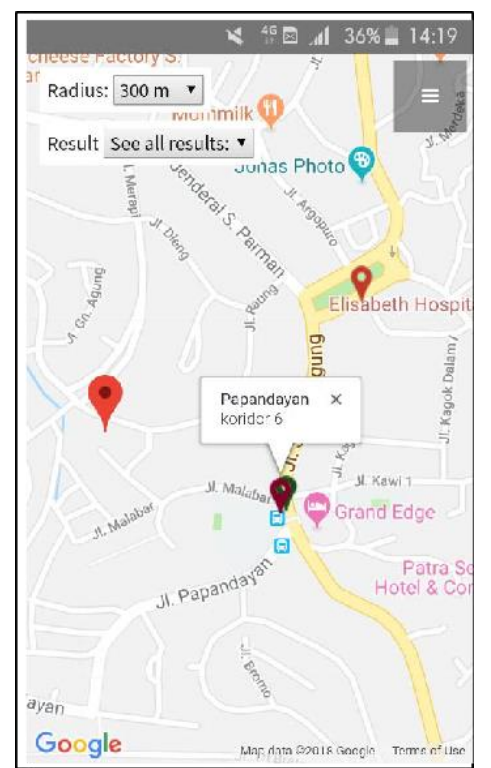

Gambar 11. Halaman Halte Terdekat

4. Halaman Cari Rute

Pencarian rute didasarkan pada shelter keberangkatan dan shelter tujuan yang diinputkan pengguna seperti pada gambar 12. Data yang diinputkan kemudian akan di eksekusi untuk mencari rute yang sesuai. Proses pencarian rute menggunakan algoritma dijkstra yang 
diimplementasikan dalam bahasa pemrograman PHP.

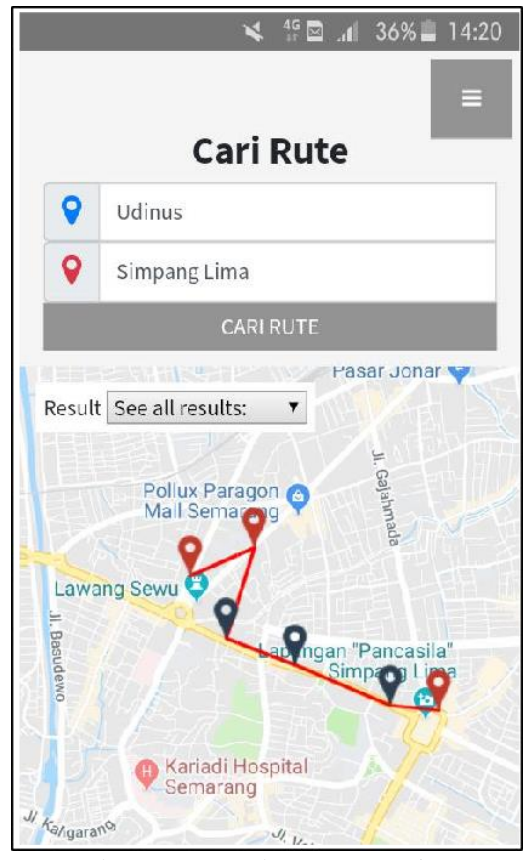

Gambar 12. Halaman Cari Rute

\subsection{Integrasi dan Uji Aplikasi}

Pengujian sistem menggunakan metode blackbox yang hasilnya menunjukkan sistem dapat menghasilkan output seperti rancangan. Selain itu, menggunakan metode UAT untuk mengetahui tanggapan user mengenai aplikasi BRT Trans Semarang yang telah dikembangkan. Pengujian dilakukan dengan memberikan kuisioner dengan 15 pertanyaan. Kuisioner diberikan kepada 30 reponden pengguna BRT Trans Semarang. Berikut pada tabel 1 merupakan hasil pengujian UAT.

Tabel 1. Pengujian User Acceptance Test

\begin{tabular}{|c|c|c|c|c|c|c|}
\hline \multirow{2}{*}{$\mathrm{NO}$} & \multirow{2}{*}{ Pertanyaan } & \multicolumn{5}{|c|}{ Pilihan Jawaban } \\
\hline & & STS & TS & $\mathrm{C}$ & $\mathrm{S}$ & SS \\
\hline 1. & $\begin{array}{l}\text { Apakah penggunaan aplikasi mudah untuk } \\
\text { dipahami? }\end{array}$ & 0 & 0 & 2 & 13 & 15 \\
\hline 2. & $\begin{array}{l}\text { Apakah tampilan aplikasi mudah untuk } \\
\text { dipahami? }\end{array}$ & 0 & 1 & 7 & 13 & 9 \\
\hline 3. & Apakah menu peta halte dapat berfungsi? & 0 & 0 & 0 & 12 & 18 \\
\hline 4. & $\begin{array}{l}\text { Apakah menu halte terdekat dapat } \\
\text { berfungsi? }\end{array}$ & 0 & 1 & 1 & 11 & 17 \\
\hline 5. & Apakah menu cari rute dapat berfungsi? & 0 & 0 & 1 & 14 & 15 \\
\hline 6. & $\begin{array}{l}\text { Apakah filter halte dalam menu peta halte } \\
\text { dapat berfungsi? }\end{array}$ & 0 & 0 & 1 & 13 & 16 \\
\hline 7. & $\begin{array}{l}\text { Apakah menu radius dalam pencarian halte } \\
\text { terdekat dapat berfungsi? }\end{array}$ & 0 & 1 & 2 & 15 & 12 \\
\hline 8. & Apakah navigasi menu dapat berfungsi? & 0 & 1 & 1 & 13 & 15 \\
\hline 9. & $\begin{array}{l}\text { Apakah aplikasi dapat memberikan } \\
\text { informasi letak halte di } 6 \text { koridor? }\end{array}$ & 0 & 1 & 3 & 16 & 10 \\
\hline 10. & $\begin{array}{l}\text { Apakah aplikasi dapat memberikan } \\
\text { informasi letak halte berdasarkan koridor? }\end{array}$ & 0 & 3 & 8 & 11 & 8 \\
\hline 11. & $\begin{array}{l}\text { Apakah menu peta halte dapat memberikan } \\
\text { informasi letak halte transit? }\end{array}$ & 0 & 3 & 1 & 9 & 17 \\
\hline
\end{tabular}




\begin{tabular}{clllllc}
\hline \multirow{2}{*}{ NO } & \multicolumn{1}{c}{ Pertanyaan } & \multicolumn{5}{c}{ Pilihan Jawaban } \\
\cline { 3 - 6 } & STS & TS & C & S & SS \\
\hline 12. & $\begin{array}{l}\text { Apakah aplikasi dapat membantu dalam } \\
\text { pencarian halte terdekat? }\end{array}$ & 0 & 2 & 1 & 9 & 18 \\
13. & $\begin{array}{l}\text { Apakah aplikasi dapat membantu dalam } \\
\text { pencarian rute ke halte tujuan? }\end{array}$ & 0 & 0 & 5 & 13 & 12 \\
14. $\begin{array}{l}\text { Apakah aplikasi memberikan informasi } \\
\text { dengan jelas? }\end{array}$ & 0 & 0 & 8 & 12 & 10 \\
15. & $\begin{array}{l}\text { Apakah informasi yang diberikan aplikasi } \\
\text { mudah untuk dipahami? }\end{array}$ & 0 & 0 & 6 & 13 & 11 \\
$\quad$ Total & 0 & 13 & 47 & 187 & 203 \\
\hline$\quad$ Persentase & $0 \%$ & $3,1 \%$ & $9,6 \%$ & $41,6 \%$ & $45,8 \%$ \\
\hline
\end{tabular}

Berdasarkan hasil user acceptance test, rata-rata responden memberikan penilaian bahwa aplikasi memiliki tampilan yang menarik, mudah dipahami, semua menu dalam aplikasi dapat berfungsi, serta dapat memberikan informasi yang mudah dipahami. Sehingga dapat disimpulkan bahwa aplikasi dapat diterima oleh pengguna.

\section{KESIMPULAN}

Aplikasi BRT Trans Semarang yang menjadi tujuan penelitian telah berhasil dikembangkan. Aplikasi ini diharapkan dapat membantu dan memudahkan para pengguna sarana transportasi umum BRT atau masyarakat yang ingin menggunakannya. Fitur peta halte dalam aplikasi dapat memberikan informasi tentang letak shelter di 7 koridor serta menambahkan fitur filter halte untuk memberikan informasi 7 rute koridor. Fitur pencarian rute dalam aplikasi dapat memberikan infromasi rute beserta koridor dan shelteryang dilalui. Selain itu, aplikasi juga menambahkan fitur pencarian halte terdekat untuk dapat memberikan informasi halte terdekat dari lokasi pengguna. Dan berdasarkan hasil pengujian menggunakan UAT dengan 30 responden pengguna BRT yang dipilih secara acak, menunjukkan aplikasi dapat diterima oleh pengguna berdasarkan kemudahan penggunaan dan informasi yang diberikan aplikasi mudah dipahami.

\section{SARAN}

Aplikasi dapat dikembangkan lebih baik lagi dengan mengoptimalkan fitur pencarian halte terdekat dengan cara memberikan informasi rute dari lokasi pengguna menuju lokasi halte. Fitur-fitur lain dapat ditambahkan seperti jadwal keberangkatan masing-masing BRT di setiap koridor sehingga pengguna tidak perlu menunggu terlalu lama di halte.

\section{DAFTAR PUSTAKA}

[1] Trans Semarang, 2018, Profil BRT BLU UPTD Trans Semarang Kota Semarang, https://drive.google.com/file/d/1rsozbVUnz_p181fwzX3NzUToJfabBjwX/view, diakses tanggal 20 Nopember 2019

[2] Widodo, Dwi Ardana, 2016, Aplikasi Pencarian Rute Jalur Bus Trans Semarang Menggunakan Algoritma Dikstra, Skripsi, Departemen Ilmu Komputer/Informatika, Fakultas Sains dan Matematika, Universitas Diponegoro, Semarang 
[3] Indiarto, Wibisono, Somantri, Maman, 2017, Perancangan Aplikasi Informasi Jadwal dan Rute Bus Rapid Transit Trans Semarang Berbasis Sistem Operasi Android, Jurnal Transmisi, vol.19, no. 3, Juli 2017

[4] Rahmandhani, Luthfi, Awaluddin, Moehammad, Nugraha, Arief Laila, 2018, Pembuatan Aplikasi Bus Trans Semarang Berbasis Mobile GIS Pada Smartphone Android, Jurnal Geodesi Undip, vol.7, no.4, Oktober 2018

[5] Junglas, Iris A., Watson, Richard T., 2008, Location-based Services: Evaluate User Perceptions of Location-tracking and Location-awareness Services, Journals Communication of The ACM, vol.51, no.3, March 2008

[6] Hoque, Md. Ziaul, 2016, Basic Consept of GPS and Its Applications, 2016, IOSR Journal of Humanities and Social Science (IOSR-JHSS), vol.21, issue 3, ver. II, March 2016, pp 31-37

[7] Skyshi, 2018, Manajemen Proyek: Waterfall atau Agile? Mana Lebih Baik?, https://medium.com/skyshidigital/manajemen-proyek-waterfall-atau-agile-mana-lebih-baikb92901f88159, diakses tanggal 28 Nopember 2019

[8] A. Dennis, B. H. Wixom dan R. M. Roth, 2010, System Analysis and Design, John Wiley \& Sons, Inc, US

[9] K. Barclay dan J. Savage, 2004, Object-Oriented Design with UML and Java, Elsevier Butterworth-Heinemann, Burlington 